\title{
Políticas de Comércio Internacional: uma análise para o comércio da soja
}

Eduardo Rodrigues Sanguinet ${ }^{1}$

Daniel Arruda Coronel ${ }^{2}$

Resumo: Este artigo objetiva avaliar como as práticas de políticas comerciais impactam os principais atuantes no mercado internacional de soja. Aplicou-se o modelo de Equilíbrio Geral Computável GTAP (Global Trade Analysis Project), pelo qual foi possível simular cenários de adoção de políticas, mensurar seus efeitos sobre a produção, os preços e a balança comercial dos países que atuam no mercado de soja. No cenário onde se simulou que a China elimina tarifas de importação para o Brasil, Argentina e EUA, os efeitos para o mercado foram de elevação dos preços e das quantidades exportadas para esses três países e redução do preço da soja chinesa. Concluiu-se que incentivos à produção e à exportação, através de subsídios governamentais, são formas eficazes de tornarem seus países mais competitivos e, nesse contexto, mostrou-se que a China pode exercer forte pujança no mercado da soja, de acordo com a política adotada pelo governo.

Palavras-Chave: Complexo soja. Políticas Comerciais. GTAP.

Classificação JEL: F13, R13, G18

1 Doutorando noPrograma de pós graduação em Economia do Desenvolvimento da Pontifícia

Universidade Católica do Rio Grande do Sul.

2 Professor adjunto na Universidade Federal de Santa Maria (UFSM). 


\title{
International Trade Policies: an analysis for the trade of soybean
}

\begin{abstract}
This article aims to evaluate how the practices of trade policies impact the key players in the international soybean market. The Computable General Equilibrium model GTAP (Global Trade Analysis Project) was applied and it was possible to simulate scenarios for the adoption of policies, measure their effects on production, prices and the trade balance of countries that participate in the soybean market. In the scenario where it was simulated that China eliminated import tariffs for Brazil, Argentina and USA, the effects on the market were of high prices and quantities exported for these three countries as well as the reduction of price of Chinese soybeans. It was concluded that incentives for production and exports, through government subsidies are effective ways to make their countries more competitive and, in this context, it was shown that China can exert strong power in the soybean market, according to the policy adopted by government.
\end{abstract}

Keywords: Soybean Complex. Trade Policy. GTAP.

\section{Introdução}

A partir de 1994, a liberalização do comércio agrícola passou a compor as rodadas de negociações da Organização Mundial do Comércio (OMC). Em decorrência disso, as disputas do comércio internacional de produtos agrícolas se intensificaram, pois os países passaram a adotar diversas ações protecionistas impostas pelos seus governos, tais como imposição de tarifas de importação, incentivos por meio de subsídios e limitação de quotas para importação. A adoção de tais medidas colaborou com a promoção de discussões acerca da forma como cada economia pode proteger seu comércio em âmbito internacional.

As medidas protecionistas são, de acordo com Costa (2012), políticas comerciais praticadas pelos países em decorrência da evolução institucional do comércio internacional. Genericamente, as principais práticas de políticas adotadas por um determinado país com a finalidade de proteger seu comércio e produção são determinação de subsídios e implementação de tarifas e quotas, incluindo estratégias de reação às políticas dos demais países, sejam eles competidores ou importadores. Os efeitos destas medidas para as relações de mercado são diversos, incluindo o ganho de participação no mercado ou a perda de competitividade, por exemplo. Alguns trabalhos empíricos analisaram os impactos que essas medidas adotadas pelos governos para o caso da comercialização agrícola, onde se verifica que os efeitos dessas políticas são significativos para o comércio internacional dos países afetados por elas (Yu 
e Frandsen, 2005; Flôres, 1997; Conforti e Salvatici, 2004; Nassar, 2004).

O Brasil, no que se refere a vantagens competitivas, destaca-se em relação à commodity soja. De acordo com Coronel et al. (2009), os mercados internacionais de grão, farelo e óleo de soja são exemplos de segmentos concentrados em que Argentina, Brasil e Estados Unidos apresentam poder de mercado, ou seja, podem aumentar lucrativamente o preço de seu produto por meio da redução da quantidade produzida. Na comercialização de produtos agrícolas, o mercado internacional do complexo de soja (grão, farelo e óleo) se caracteriza pelo domínio, desde meados dos anos 70, em termos de produção e exportação, de três países - Brasil, Argentina e Estados Unidos da América (EUA) - com cerca de $75 \%$ do que é produzido mundialmente.

As exportações brasileiras se destacam tanto para os grãos quando para os derivados (farelo e óleo de soja); os EUA são os maiores exportadores mundiais de grãos, com pequena participação no comércio de derivados; e a Argentina especializou-se nas exportações de farelo e óleo de soja. A dinâmica e relatividade das participações de mercado desses países não é algo objetivamente definido e considera-se que estes três países, a partir de práticas de políticas comerciais, influem de forma direta no desempenho comercial dos demais. Em termos de destinos da soja exportadora, segundo a FAO (2014) e Coronel et. al. (2009), tem-se que a China e a União Europeia são os principais importadores do complexo e que a adoção de barreiras comerciais ou medidas protecionistas por ambos provocaria impactos nas balanças comerciais agrícolas dos países exportadores.

Com base na influência das práticas de políticas comerciais adotadas por alguns países sobre o desempenho comercial de outros, este trabalho objetiva verificar e analisar, por meio da aplicação de um modelo de Equilíbrio Geral Computável, os efeitos das políticas comerciais adotadas pelos principais concorrentes e compradores sobre os principais exportadores do complexo de soja e sobre o mercado como um todo.

O presente trabalho está divido em cinco seções, a incluir esta introdução. A segunda mostra o panorama da produção de soja, em âmbito mundial, a fim de retratar as relações de produção e comercialização do complexo de soja. A seção seguinte apresenta os procedimentos metodológicos do estudo. A quarta seção apresenta os resultados e efeitos de práticas comerciais sobre o mercado internacional e, por fim, a última parte do artigo traz as conclusões do estudo.

\section{Comércio internacional do complexo de soja}

A soja em grão e seus derivados (farelo e óleo de soja) caracterizam-se como os produtos mais comercializados mundialmente, devido à variedade de formas do seu consumo, que inclui desde alimentação humana até o uso na indústria 
farmacêutica, com utilização do farelo na produção de proteínas animais, avicultura, suinocultura e também na pecuária e do óleo de soja, como importantes fontes de matéria-prima para diferentes setores industriais (Reetz, 2006).

O mercado internacional deste complexo é caracterizado pela existência de uma competição imperfeita. As produções e exportações mundiais estão centradas em um número reduzido de países: Estados Unidos (EUA), Brasil e Argentina. Historicamente, esse mercado era controlado praticamente pelos EUA, que, por volta da década de 1970, era responsável por cerca de $90 \%$ das exportações de soja em grãos e mais de 60\% de seus derivados (Susanto, 2006). No entanto, com a entrada do Brasil, nos anos 1970, e da Argentina, na década seguinte, houve a formação de uma divisão do mercado entre esses países, caracterizando-o como uma estrutura oligopolizada.

A Figura 1 mostra a produção bruta da soja, em milhões de toneladas, retratando a participação da produção brasileira, argentina e norte-americana nas últimas décadas. Observa-se que os três países produzem uma grande quantidade de soja e que há um aumento gradativo da produção do complexo no Brasil e na Argentina, onde se tem que, para o caso argentino, em 1990, o país produzia 21,89\% do que foi produzido em 2011, enquanto o Brasil produzia, no início da década de 1990, cerca de $26 \%$ do total de 2011. Apesar dos três países apresentarem um nível de produção alto, os Estados Unidos se mostram pioneiros em todos os anos observados. De modo geral, é possível afirmar que os EUA se consolidaram como o país que mais produz, sendo seguido pelo Brasil e logo pela Argentina. 
FIGURA 1 - VOLUMES DE PRODUÇÃO DE SOJA (1990 - 2011)

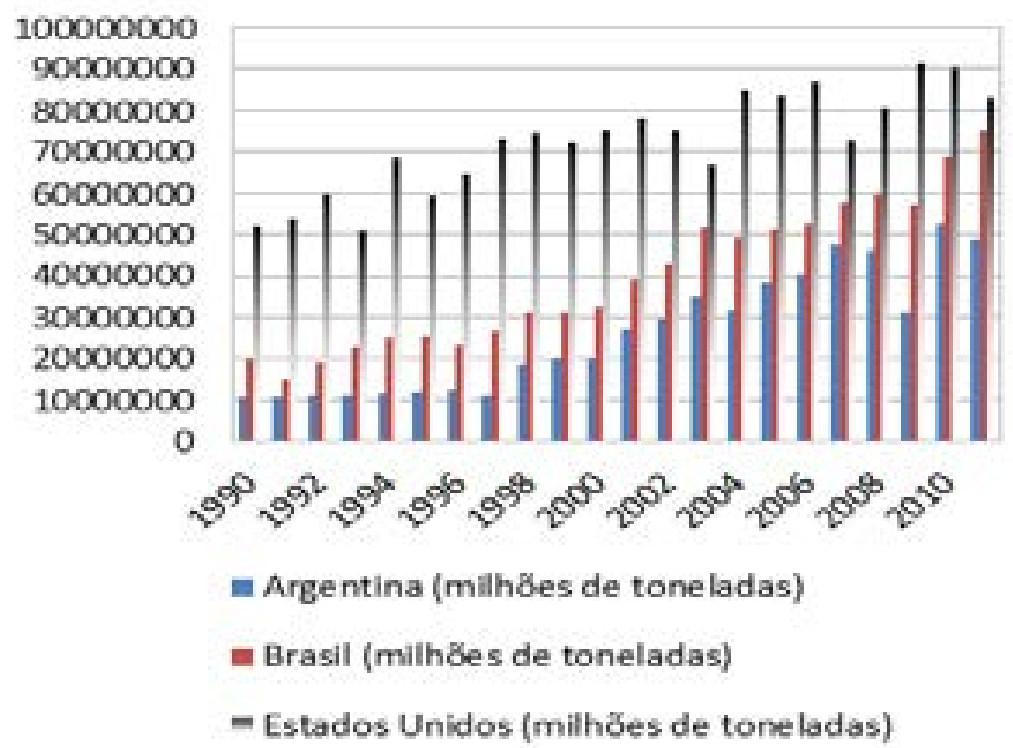

Fonte: Elaboração própria a partir de FAOSTAT (2014).

A partir de 1998, o Brasil passou a produzir cada vez mais, devido principalmente às mudanças no regime cambial adotado no país. A Argentina, por sua vez, mostrou-se com uma produção relativamente alta, mas sem demonstrar uma tendência de ampliação da produção, revelando-se instável quanto ao total de soja produzida, com variações de volume total produzido. Valerini (2006) afirma que a produção de soja apresenta uma tendência crescente e que a participação do Brasil e da Argentina tem contribuído sistematicamente para tal crescimento. Em 1990, a produção mundial correspondeu a 108,4 milhões de toneladas métricas, passando para 126,9 milhões em 1995. Em 2005, tal produção equivale a aproximadamente 214,5 milhões de toneladas. Assim, entre 1990 a 2005, o crescimento da produção mundial é de 99,7\%, apresentando uma taxa de crescimento média anual de 4,8\%.

As discussões referentes à competitividade e à participação no mercado internacional de soja estão fortemente relacionadas aos efeitos de mudanças políticas ocorridas nas últimas décadas nos três principais exportadores. Os EUA, através de suas últimas duas leis agrícolas, aumentaram os subsídios a seus produtores de soja. Brasil e Argentina adotaram, em 1999 e 2002, respectivamente, regimes de câmbio flutuante, com as desvalorizações de suas moedas contribuindo para o aumento de suas competitividades no setor de soja, pelo menos no curto prazo (Sampaio et al., 2006). 
Na Argentina, o cenário político que levou à desvalorização de sua moeda (desvalorização de 70\% do peso frente ao dólar em 2002) foi de crise econômica, com o colapso do sistema bancário (Sampaio et al., 2006). Mesmo assim, o setor agrícola reagiu rapidamente e produtores de soja, assim como os brasileiros, foram beneficiados na medida em que já haviam realizado os gastos com insumos, e a receita, com as vendas realizadas posteriormente, foi bem maior em moeda local. Muitos produtores, após a desvalorização, também passaram a negociar o produto diretamente como moeda, adquirindo máquinas e insumos e "pagando" com mercadoria. A Figura 2 retrata a evolução temporal das exportações do complexo de soja produzido na Argentina.

FIGURA 2 - EXPORTAÇÕES DO COMPLEXO DE SOJA, EM TONELADAS (1990-2011)

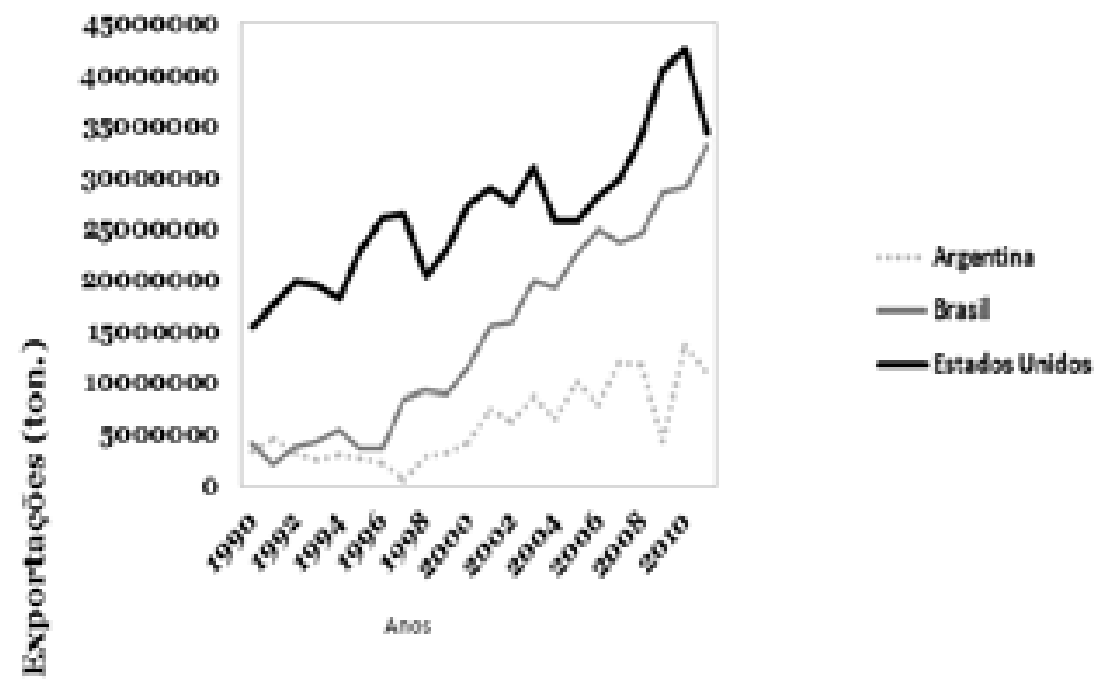

Fonte: Elaboração própria baseada em FAOSTAT (2014).

Os efeitos da desvalorização e da mudança de regime cambial são nitidamente retratados (Figura 2). A partir de 1996, a soja brasileira passa a apresentar uma evolução crescente na participação no comércio internacional. Brandão e Lima (2006) analisaram, com base na nova lei agrícola, os efeitos dos subsídios americanos sobre o mercado internacional de soja, através de um modelo econométrico, e concluíram que o suporte americano tem impacto significativo no comércio exterior, já que 50\% do aumento da produção será exportado. Essas mudanças de participação dos países na comercialização mundial da soja podem ser explicadas por alguns fatores, tais como mudanças 
de regimes cambiais e facilidades comerciais impostas por seus governos. As alterações de formulações de políticas agrícolas, voltadas a subsídios, por exemplo, são fontes de mudanças estruturais na agricultura, de regionalização e concentração da produção, e também da internacionalização das atividades produtivas e a ocupação dos segmentos de maior valor agregado, sobretudo nos serviços alimentares, favorecendo o aumento da produtividade, a qualidade do produto e a maior inserção no mercado internacional (Valerini, 2006).

A competitividade tende a provocar uma transformação na agricultura a fim de aumentar a produtividade em prol da melhoria econômica da produção. A mesma competitividade, porém, provoca o surgimento de práticas protecionistas que dificultam a comercialização, frente às barreiras que impedem o aumento das exportações via restrições à entrada de produtos em alguns países. Estas práticas reduzem o crescimento do mercado para outros países, inibindo a concorrência através de medidas que inviabilizam ou impedem o desenvolvimento da atividade nos demais países, a fim de manter maior parcela do mercado, onde alguns países utilizam, excessivamente, instrumentos de proteção da agricultura a fim de ganhar espaço frente aos concorrentes e aumentar os lucros.

De acordo com Coronel (2008), os maiores importadores do óleo de soja brasileiro, de 1995 a 2008, foram China, Irã, Índia e União Europeia. Esta última vem reduzindo gradativamente as importações de óleo, visto que está intensificando o processamento da commodity. Conforme a Secex (Secretaria do Comércio Exterior, 2008), o país da União Europeia que mais importa óleo é a Alemanha. Destaca-se ainda que, desde o final da década de 1990, Egito, Blangladesh e Marrocos vêm se configurando como importantes mercados para as importações do óleo produzido no Brasil. Dados mais atuais da FAO (2014) mostram que a China e a União mantêm-se como os principais destinos para o complexo de soja produzido tanto pela Argentina quanto pelo Brasil e Estados Unidos.

Com a mesma tendência de aumento da produção e das exportações, ou seja, aumento da participação no mercado, a Argentina e o Brasil ganharam participação mais do que marcante ao longo das duas décadas retratadas. A China tanto participou mais das compras do complexo de soja quanto intensificou as compras dos países latino-americanos citados, primordialmente a partir de 1999. Esse fato pode ser atribuído a mudanças nos regimes cambiais no Brasil e na Argentina, cujas moedas tornaram-se mais competitivas internacionalmente.

Com base nos dados da FAO (2014), nas décadas de 1990 e 2000, os Estados Unidos se destacaram como os principais exportadores de soja para a China. Contudo, o Brasil merece certo destaque, posto que anualmente sua participação nesse comércio aumenta e, em alguns momentos, se equipara aos EUA ou o supera. A Argentina, apesar de desempenhar um papel importante para o volume do complexo que a China importa, não conseguiu alcançar os 
patamares dos outros dois países e, entre 2007 e 2008, mostrou uma queda, momento esse em que o Brasil se beneficiou.

Cabe destacar também o peso que as importações da União Europeia desempenham para a balança comercial da pauta exportadora de soja para os três países estudados. Para Coronel (2008), a União Europeia passou a manter relações comerciais de compra de soja mais significativas a partir de 1995 , mantendo-as até os anos atuais. Em relação às importações de soja pelos países da União Europeia, ${ }^{1}$ tem-se que o Brasil aumentou drasticamente suas relações de venda para esse destino. Em 1990, o volume de soja exportada para a União Europeia estava em torno de 2,6 milhões de toneladas, passando para 9,4 milhões em 2007. Os Estados Unidos, porém, caminharam em movimento contrário ao brasileiro, uma vez que, em 1990, cerca de 5,6 milhões de toneladas eram exportadas, passando para 3,2 milhões em 2007. A Argentina acompanhou a trajetória norte-americana, perdendo espaço nesse comércio (FAo, 2014).

\section{Metodologia}

Inicialmente, foi feita uma revisão bibliográfica, a partir de outros estudos e pesquisas que trataram da temática do comércio internacional de soja, momento em que se analisaram dados secundários referentes à produção e comercialização mundial. A segunda etapa ${ }^{2}$ consistiu na aplicação do modelo GTAP (Global Trade Analysis Project).

A ideia geral do modelo GTAP consiste num sistema de equações simultâneas que expressam as decisões dos agentes, simplificando o comportamento real, onde há uma sucessão de decisões. Essa sucessão pode ser entendida, de forma simplificada, iniciando-se com os preços domésticos, de exportação e mundiais ${ }^{3}$. Segundo Gurgel, Pereira e Teixeira (2010), os modelos de equilibro geral são estáticos, multirregionais e multissetoriais, permitindo que a produção e distribuição de bens e serviços sejam representadas em nível mundial. A estrutura da demanda final das regiões é composta por despesas públicas e privadas, tais como bens e serviços, em que os consumidores buscar a maximização do seu bem-estar, de acordo com a restrição orçamentária, e os níveis de investimento e produção do setor público são fixos. Os setores produtivos das economias combinam insumos intermediários e fatores pri-

1 Os países da União Europeia em cujos dados e este estudo é baseado são os 25 participantes em 2008, a saber: Alemanha, Áustria, Bélgica, Bulgária, Chipre, Croácia, Dinamarca, Eslováquia, Eslovênia, Espanha, Estônia, Finlândia, França, Grécia, Hungria, Irlanda, Itália, Letônia, Lituânia, Luxemburgo, Malta, Países Baixos, Polônia, Portugal, Reino Unido, República Checa, Romênia, Suécia. 2 Essa etapa é baseada no aporte teórico desenvolvido por Coronel (2010). $3 \mathrm{O}$ desenvolvimento do modelo e seus pressupostos é descrito em Sampaio e Sampaio (2007). 
mários de produção (capital, trabalho qualificado, trabalho não qualificado, terra e recursos naturais) com vistas em minimizar custos, dada a tecnologia existente. A base de dados do GTAP inclui os fluxos bilaterais de comércio entre países e regiões, bem como os custos de transporte, tarifas de importação e impostos (ou subsídios) às exportações.

Figueiredo (2001) salienta que o GTAP combina fatores primários com fatores intermediários, produzindo bens para o consumo final (famílias, governo e firmas) e vendendo bens de investimento para satisfazer à demanda de poupança das famílias. O equilíbrio poderá ser atingido pela exportação e importação de produtos e fatores, onde o modelo insere o que considera por "resto do mundo". Todos os agentes são otimizadores e pagam impostos, da mesma forma que poupam. As relações entre os agentes e as regiões são mostradas na Figura 3.

No modelo, a diferenciação de produto entre bens domésticos, importados e das regiões de importação se dá de acordo com a hipótese de Armington ${ }^{4}$, que permite a troca bilateral para cada categoria de um determinado bem, dependendo da facilidade de substituição entre produtos de regiões diferentes. A terra $(T)$, o capital $(K)$, o trabalho $(L)$ especializado e não especializado e os recursos naturais são usados na produção e são plenamente empregados. De acordo com Sampaio (2009), o modelo incorpora relações como mudança na demanda devido a alterações na renda, na estrutura das indústrias associadas às variações na relação capital-trabalho e alterações nos preços mundiais, como resultados das mudanças na demanda e na oferta mundial, além de alterações na dotação de fatores.

Neste trabalho, utilizou-se a última versão do GTAP (versão 8) em que foram incorporadas as tarifas e subsídios praticados pelos países, tanto as referentes ao mercado interno como as aplicadas às exportações e importações. Introduzidas as alterações desejadas, o modelo gera resultados referentes à produção, à demanda e ao preço, ao preço dos fatores, às exportações e importações, ao preço e à balança comercial, ao PIB e ao bem-estar, representado pela utilidade dos consumidores e pela variação equivalente. A base de dados baseia-se nas informações sobre fluxos comerciais e variáveis internas para cada um dos países envolvidos, em que foram detalhadas 129 regiões e 57 setores, com referências duplas dos anos de 2004 e 2007. 


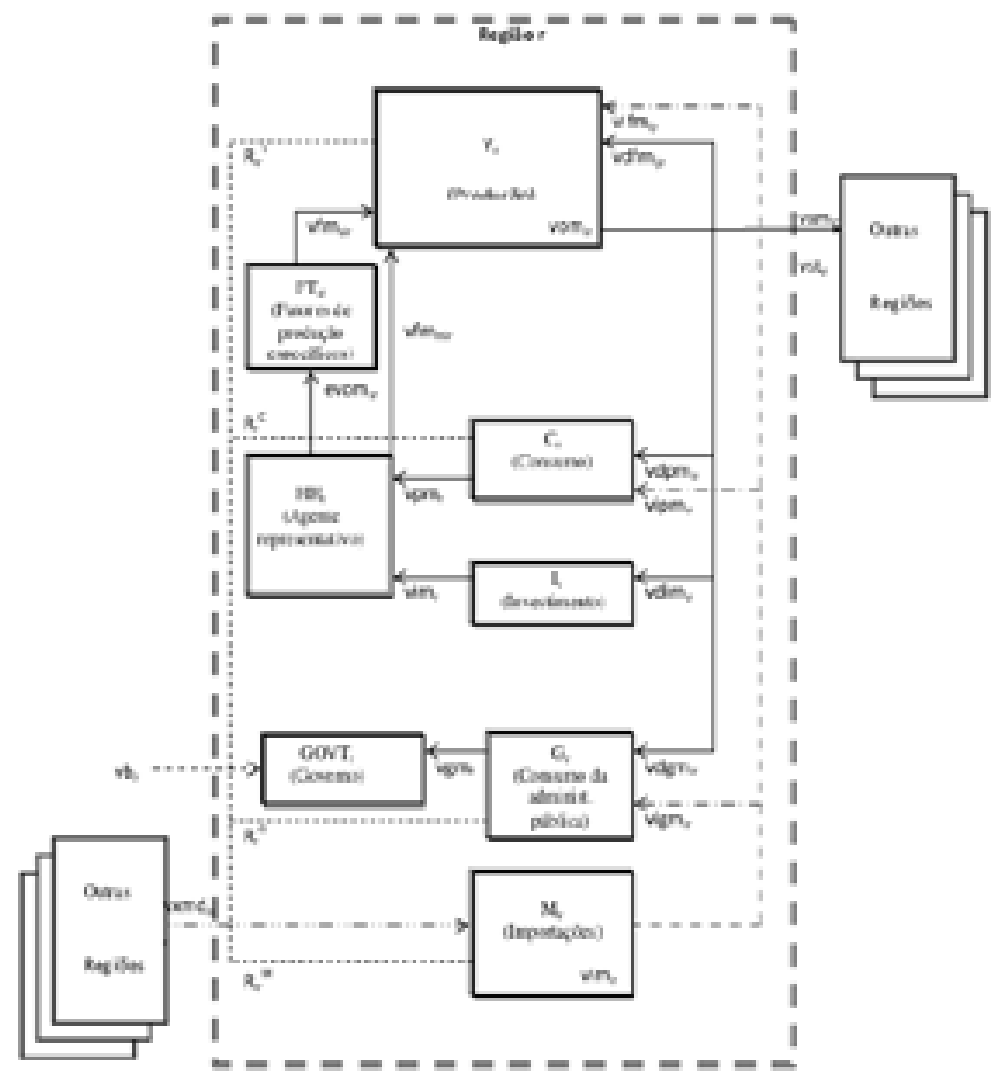

Fonte: Gurgel, Pereira E Teixeira (2010).

A Figura 3 apresenta a estrutura geral do modelo GTAP e as relações entre os agentes (famílias, governos e firmas). Os setores e bens são representados pelos índices $i$ e $j$; os países e regiões, por $r$ e $s$; os fatores de mobilidade livre dentro de cada região, por $f$ e m; e por fim, os fatores de produção fixos (terra e outros recursos naturais) são representados por $f$ e s. As variáveis do modelo são: $Y_{i r}$, a produção do bem $i$, na região $r ; C_{r}, I_{r}$ e $G_{r}$, respectivamente, o consumo privado, o investimento e o consumo público; $M_{j r}$, as importações do bem $j$ pela região $\mathrm{r}$; $H H_{r}$, o agente consumidor representativo (ou domicílio); e $G O V T_{r}$, o setor público ou governo; $F T_{s r}$ uma atividade por meio da qual os fatores de produção específicos são alocados para setores particulares. 
As linhas sólidas ou pontilhadas de forma irregular representam os fluxos nos mercados de fatores e de bens. As linhas pontilhadas de forma irregular referem-se ao pagamento de impostos, enquanto as linhas verticais à direita representam os mercados de bens domésticos e importados. A produção doméstica $\left(v o m_{i r}\right)$ é distribuída entre exportações $\left(v x m d_{i r s}\right)$, serviços de transporte internacional $\left(v s t_{i r}\right)$, demanda intermediária $\left(v d f m_{i j}\right)$, consumo privado $\left(v d p m_{i r}\right)$, investimento $\left(v \operatorname{dim}_{i r}\right)$ e consumo do governo $\left(v d g m_{i r}\right)$.

Coronel (2010) e Gurgel, Pereira e Teixeira (2010) desenvolveram matematicamente as identidades contábeis da base de dados do GTAP. A identidade contábil, representada pelas matrizes de contabilidade social, referente à produção doméstica, é apresentada pela Equação (1).

$$
v o m_{i r}=\sum_{s} v x m d_{i r s}+v s t_{i r}+\sum_{j} v d f m_{i j r}+v d p m_{i r}+v d g m_{i r}+v d i m_{i r}
$$

Bens importados, representados agregadamente por vim $_{\mathrm{ir}}$, são utilizados no

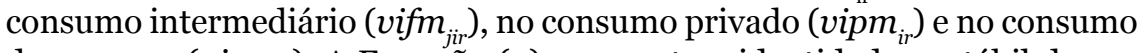
do governo $\left(\right.$ vigm $\left._{i r}\right)$. A Equação (2) apresenta a identidade contábil desses fluxos.

$$
\operatorname{vim}_{i r}=\sum_{j} v_{i f m_{i j r}}+\text { vipm }_{i r}+\text { vigm }_{i r}
$$

Na produção de $Y_{i r}$ incluem-se insumos intermediários (domésticos e importados), fatores de produção móveis ( $v f m_{f i r}, f$ e $m$ ) e consumo do agente público $\left(v_{i g m_{i r}}\right.$ ). A renda dos fatores de produção é distribuída ao agente representativo. O equilíbrio nos mercados de fatores é dado por uma identidade que relaciona o valor do pagamento dos fatores com a renda destes (Equação 3).

$$
\sum_{i} v f m_{f i r}=e v o m_{f r}
$$

Nos mercados internacionais, o equilíbrio entre oferta e demanda requer condições em que as exportações do bem $i$ na região $r\left(v x m_{i r}\right)$ sejam iguais às importações do mesmo bem por todos os parceiros comerciais $\left(v x m d_{i r s}\right)$, como representado na Equação (4). Da mesma forma, condições de equilíbrio aplicam-se também aos serviços de transporte internacional, em que a oferta agregada do serviço $j, v t_{j}$, é igual ao valor dos serviços de transporte nas exportações (Equação 5). O equilíbrio entre oferta e demanda, no mercado de serviços de transporte, iguala a oferta desses serviços à soma dos fluxos 
bilaterais de serviços de transporte adquiridos nas importações de bens $\left(v t w r_{j i s r}\right)$, como na Equação (6).

$$
\begin{gathered}
v x m_{i r}=\sum_{s} v x m d_{i r s} \\
v t_{j}=\sum_{r} v s t_{j r} \\
v t_{j}=\sum_{r} v t w r_{j i s r}
\end{gathered}
$$

Os impostos e as transferências geram receitas, que são representadas por Re indicadas pelas linhas pontilhadas na Figura 1. Os fluxos de impostos consistem de impostos indiretos na produção e exportação $\left(R_{i r}{ }^{Y}\right)$, no consumo $\left(R_{r}^{C}\right)$, na demanda do governo $\left(R_{r}{ }^{G}\right)$ e nas importações $\left(R_{i r}{ }^{M}\right)$. A renda do governo também inclui impostos diretos ao agente representativo, representados por $R_{r}^{H H}$, bem como transferências do exterior, $v b_{r}$. A restrição orçamentária do governo pode ser representada pela Equação (7).

$$
v g m_{r}=\sum_{i} R_{i r}^{Y}+R_{i r}^{C}+R_{r}^{G}+\sum_{i} R_{i r}^{H}+R_{r}^{H H}+v b r
$$

A restrição orçamentária do agente representativo relaciona a renda dos fatores de produção, descontada dos pagamentos de impostos, com as despesas de consumo e investimento privado, como na Relação (8).

$$
\sum_{f} \text { evom }_{f r}-R_{r}^{H H}=v p m_{r}+\operatorname{vim}_{r}
$$

Esse desenvolvimento aritmético permite que sejam feitas, em relação à consistência da base de dados do GTAP (a partir das matrizes de insumo-produto) e contabilidade social, algumas considerações. A primeira é o equilíbrio de mercado (oferta igual à demanda para todos os bens e fatores de produção) e o balanço da renda (renda líquida igual à despesa líquida). Um terceiro conjunto de identidades diz respeito aos lucros operacionais líquidos nos setores da economia, uma vez que os custos com insumos intermediários e fatores de produção se igualam ao valor da produção, e os lucros econômicos, a zero. Tal condição se aplica a cada um dos setores produtivos e atividades, conforme as Equações (9) a (15). 


$$
\begin{gathered}
Y_{i r}: \sum_{f} v \text { fm }_{f i r}+\sum_{j}\left(v i f m_{j i r}+v i f m j i r\right)+R_{i r}^{Y}=v o m_{i r} \\
M_{i r}: \sum_{s}\left(v x m d_{i s r}+\sum_{j} v t m r_{j i s r}\right)+R_{i r}^{M}=v i m_{i r} \\
C_{r}: \sum_{i}\left(v d p m_{i r}+v \operatorname{vipm}_{i r}\right)+R_{i r}^{G}=v g m_{r} \\
G_{r}: \sum_{i}\left(v d g m_{i r}+v i g m_{i r}\right)+R_{i r}^{G}=v g m_{r} \\
I_{r}: \sum_{i} v \operatorname{dim}_{i r}=v i m_{r} \\
F T_{f r}=e v o m_{f r}=\sum_{i} v f m_{f i r} \\
\sum_{r} v s t_{j r}=v t_{j}=\sum_{i r s} v t w r_{j i r s}
\end{gathered}
$$

O fechamento do modelo considera que a oferta total de cada fator de produção não se altere, mas tais fatores são móveis entre setores, dentro de uma região. O fator terra é específico aos setores agropecuários, enquanto recursos naturais são específicos a alguns setores (de extração de recursos minerais e energia). Não há desemprego no modelo; portanto, os preços dos fatores são flexíveis. Pelo lado da demanda, investimentos e fluxos de capitais são mantidos fixos, bem como o saldo do balanço de pagamentos. Dessa forma, mudanças na taxa real de câmbio devem ocorrer para acomodar alterações nos fluxos de exportações e importações após os choques. O consumo do governo poderá alterar com mudanças nos preços dos bens, assim como a receita advinda dos impostos estará sujeita a mudanças no nível de atividade e no consumo.

Com bases nesses pressupostos do modelo, infere-se que as importações, exportações, além da demanda e oferta por moeda estrangeira determinam o câmbio, completando, assim, o ciclo com os novos preços domésticos, de exportação e de importação. Esse processo continua até a convergência do conjunto de preços para valores que garantam o equilíbrio de todos os mercados. 
Simularam-se possíveis choques de práticas comerciais, conforme as seguintes agregações:

1) Países e regiões: Brasil, Argentina, Estados Unidos (EUA), China, União Europeia e demais países;

2) Produtos: Complexo de soja ${ }^{5}$ e demais produtos;

3) Políticas comerciais: subsídios à exportação, eliminação de tarifas à importação e subsídios domésticos à produção.

As agregações fazem referência a produção, exportações e importações mundiais. A aplicação do GTAP permitiu que se avaliassem os choques resultantes da adoção de políticas pelos países. Os quatro cenários simulados foram:

1) China elimina as barreiras de importação da soja de origem brasileira, argentina e norte-americana: Nesse cenário, considerou-se que o governo chinês elimina as barreiras de importação da soja produzida pelo Brasil, Argentina e Estados Unidos, procurando conciliar os interesses internacionais dos países-membros atuantes nos mercados internacionais. A partir desse cenário, espera-se que os países sejam beneficiados com a expansão de suas pautas exportadoras do complexo de soja e que ocorra uma diminuição dos preços de importação, posta uma maior concorrência entre os exportadores.

\section{2) Brasil, Argentina e Estados Unidos subsidiam 50\% da produção} nacional de soja: A partir do incentivo à produção interna adotada pelos países que se destacam na produção e comercialização da soja, tem-se um cenário onde a capacidade produtiva da commodity se eleva, promovendo uma expansão da oferta mundial. Assim, espera-se, como impacto dessa medida de política comercial adotada pelos países, que o preço se reduza (posto o aumento da oferta nos três casos), que a quantidade exportada aumente, junto com as importações chinesas e também da União Europeia.

3) O governo chinês decide subsidiar $50 \%$ da produção doméstica de soja: Nesse cenário, há uma medida radical do governo chinês pela qual se procura incentivar a produção e competitividade da soja chinesa frente ao 5 No GTAP, o complexo de soja é representado por OSD e inclui a soja e demais oleaginosas. 
mercado internacional. Espera-se que, com tal medida, a produção de soja na China se eleve e que suas importações diminuam consideravelmente. Esse cenário incorre que a produção brasileira, argentina e norte-americana venha a ser prejudicada, pois um importante mercado consumidor tenderá a se exaurir. Concomitantemente, os preços de importação da soja tendem a apresentar inconsistências, decorrentes de uma nova conjuntura comercial do complexo.

\begin{abstract}
4) Brasil, Argentina e Estados Unidos subsidiam $50 \%$ de suas exportações de soja: Esse último cenário investiga como a ação de incentivos à exportação, por parte das três nações que mais se destacam como produtoras do complexo de soja, afetariam o mercado internacional dessa commodity. Esperam-se variações referentes aos preços de importação, com diminuições para esses três países. Também se infere a possibilidade de elevação nas exportações e quantidade produzida internamente e, para os importadores representados pela China e União Europeia, espera-se uma elevação no nível de importações.
\end{abstract}

\title{
5. Análise e discussão dos resultados
}

\subsection{Cenário 1: China elimina as barreiras de importação de soja de origem brasileira, argentina e norte-americana}

Nesse cenário, a China toma uma decisão importante para a competitividade da soja em âmbito internacional, pois concede uma maior liberdade para que se importe soja produzida no Brasil, Argentina e/ou dos Estados Unidos. De acordo com Vianna e Lima (2010), as barreiras comerciais tendem a ser eliminadas ou reduzidas à medida que os países intensificam o processo de integração, negociando acordos e/ou criando blocos econômicos. Quaisquer resultados provenientes dessas negociações trazem consequências diversas para determinados setores da economia dos países participantes. Nesse contexto, o Brasil vem participando de negociações que visam aumentar o fluxo de comércio com outros países, e sua participação nas negociações comerciais da OMC (Organização Mundial do Comércio) junto com sua inserção no Mercosul é um dos reflexos dessas iniciativas.

Vale destacar a importância que a política comercial tem para os setores econômicos e que as medidas adotadas ao final de cada processo poderão influenciar o equilíbrio do balanço de pagamentos, o nível de produção local e também variações na balança comercial. A partir da simulação em que a China elimina tarifas de importação para os produtos de soja exportados pelo 
Brasil, pela Argentina e pelos Estados Unidos, tem-se, na Tabela 1, os resultados em termos de variações de preços, quantidade produzida, importada e também exportada.

TABELA 1 - VARIAÇÕES DECORRENTES DOS EFEITOS DA POLÍTICA COMERCIAL ADOTADA PELA CHINA

\begin{tabular}{|c|c|c|c|c|c|}
\hline \multicolumn{6}{|c|}{ Variação nos preços relativos de importação $(\Delta \%)$} \\
\hline $\begin{array}{c}\text { União } \\
\text { Europeia }\end{array}$ & $\begin{array}{c}\text { Resto do } \\
\text { Mundo }\end{array}$ & Argentina & $\begin{array}{c}\text { Estados } \\
\text { Unidos }\end{array}$ & China & Brasil \\
\hline 0,000 & $-0,020$ & 0,150 & 0,060 & $-0,410$ & 0,070 \\
\hline \multicolumn{6}{|c|}{ Variação na quantidade produzida internamente $(\Delta \%)$} \\
\hline 0,020 & $-0,060$ & 0,540 & 0,380 & $-2,010$ & 0,620 \\
\hline \multicolumn{6}{|c|}{ Variação na quantidade importada no país $(\Delta \%)$} \\
\hline$-0,010$ & $-0,060$ & 0,350 & 0,200 & 2,170 & 0,190 \\
\hline \multicolumn{6}{|c|}{ Variação na quantidade exportada no país $(\Delta \%)$} \\
\hline 0,050 & $-0,650$ & 1,820 & 1,020 & 1,370 & 1,340 \\
\hline
\end{tabular}

Fonte: Elaboração própria a partir dos resultados do GTAP.

Tem-se que os efeitos de uma liberalização da comercialização de soja para a China, por meio da eliminação de tarifas de importação, afetariam variáveis macroeconômicas, primordialmente, dos países mais beneficiados por tal medida (nesse caso, os que exportam). A quantidade produzida se eleva nos três principais exportadores do complexo de soja, mas com um aumento não muito significativo, em decorrência de tal eliminação de tarifas afetar simultaneamente os três países. A relação em termos de preços de importação pagos pela China mostrou-se em elevação, com um aumento mais acentuado para a soja comercializada com a Argentina.

A quantidade da commodity importada pela China aumenta em 2,17\%, mas a quantidade exportada também aumenta em 1,37\%. Os principais exportadores veem suas quantidades relativas de exportação aumentarem também, de forma que os outros países apresentam uma leve diminuição em suas exportações (- 0,65\%). 


\subsection{Cenário 2: Brasil, Argentina e Estados Unidos deci- dem subsidiar suas produções de soja em $50 \%$}

Nesse cenário, considera-se que os governos brasileiro, argentino e norte-americano decidiram incentivar a produção doméstica de soja, de forma a aumentar a oferta para os mercados internacionais e intensificar a concorrência entre os exportadores do complexo de soja. Para Schmidtk e Shikida (2008), os efeitos de um subsídio evidenciam o interesse do Estado em possibilitar ao exportador que venda seu produto a um menor preço, de forma a reduzir os custos dos agentes exportadores. Os autores enfatizam que o subsídio da produção e/ou exportação tende a diminuir o preço internacional e a aumentá-lo no mercado interno.

TABELA 2 - VARIAÇÕES DECORRENTES DA ADOÇÃO DA POLÍTICA DE SUBSÍDIOS DA PRODUÇÃO

\begin{tabular}{cccccc}
\hline \multicolumn{7}{c}{ Variação nos preços relativos de importação $(\Delta \%)$} \\
\hline $\begin{array}{c}\text { União } \\
\text { Europeia }\end{array}$ & $\begin{array}{c}\text { Resto do } \\
\text { Mundo }\end{array}$ & Argentina & $\begin{array}{c}\text { Estados } \\
\text { Unidos }\end{array}$ & China & Brasil \\
\hline$-1,830$ & $-3,430$ & $-32,850$ & $-31,200$ & $-5,790$ & $-31,320$ \\
\hline \multicolumn{7}{c}{ Variação na quantidade produzida internamente $(\Delta \%)$} \\
\hline$-21,050$ & $-14,050$ & 24,980 & 36,470 & $-27,510$ & 34,330 \\
\hline 7,310 & Variação na quantidade importada no país $(\Delta \%)$ & \\
\hline \multicolumn{7}{c}{ Variação na quantidade exportada no país $(\Delta \%)$} \\
\hline$-47,770$ & $-48,960$ & 12,810 & 27,370 & $-41,630$ \\
\hline \multicolumn{7}{c}{-50} & $-59,370$ & $-55,100$ & $-4,040$ & $-56,380$ \\
\hline
\end{tabular}

Fonte: Elaboração própria a partir dos resultados do GTAP.

Os efeitos sobre os preços de venda da soja foram de redução para os três países exportadores, sendo na Argentina a mais acentuada (32,85\%). Como dinamicidade do incentivo à produção, nos três países, a quantidade produzida aumentou consideravelmente, destacando-se os Estados Unidos e o Brasil. Em termos de quantidade exportada, observa-se um aumento principalmente nos Estados Unidos, que teve sua pauta exportadora elevada em $27,37 \%$, seguido pelo Brasil com $16,52 \%$ e a Argentina com 12,81\%.

Na China e na União Europeia, os principais importadores, nota-se um efeito dúbio ao esperado pelos países que exportam, onde a União Europeia 
intensifica suas compras - provavelmente em decorrência da maior oferta internacional e da redução de preços, uma vez que impulsiona suas importações em 7,31\% a mais. A China, no entanto, mesmo pagando preços menores pela commodity, reduziu a quantidade importada, com 4,04\% a menos do que importava antes da adoção da política de subsídio tomada pelos países exportadores.

Nesse cenário, vê-se que a participação dos demais países no mercado internacional de soja foi afetada, uma vez que as importações globais aumentaram em cerca de $12 \%$, e as exportações foram reduzidas em cerca de $49 \%$, sendo justificadas pelo aumento da participação da Argentina, do Brasil e dos Estados Unidos como os principais exportadores.

\subsubsection{Cenário 3: O governo chinês decide subsidiar 50\% da produção doméstica de soja}

Em uma atitude de incentivo e protecionismo, o governo chinês decide subsidiar metade da produção doméstica. Para defender a produção doméstica, alguns países utilizam subsídios e elevam tarifas de importação aos produtos agrícolas, contrariando muitas vezes as regras da OMC, prejudicando, assim, exportações do mundo todo. A partir desse cenário, a Tabela 3 mostra as variações em termos de preços, quantidade produzida, nível de exportações e de importações.

TABELA 3 - VARIAÇÕES DECORRENTES DO INCENTIVO CHINÊS À PRODUÇÃO NACIONAL

\begin{tabular}{cccccc}
\hline \multicolumn{6}{c}{ Variação nos preços relativos de importação $(\Delta \%)$} \\
\hline $\begin{array}{c}\text { União } \\
\text { Europeia }\end{array}$ & $\begin{array}{c}\text { Resto do } \\
\text { Mundo }\end{array}$ & Argentina & $\begin{array}{c}\text { Estados } \\
\text { Unidos }\end{array}$ & China & Brasil \\
\hline$-0,370$ & $-1,020$ & $-3,050$ & $-1,770$ & $-40,420$ & $-1,720$ \\
\hline \multicolumn{7}{c}{ Variação na quantidade produzida internamente $(\Delta \%)$} & $-14,220$ \\
\hline$-4,130$ & $-4,170$ & $-11,800$ & $-10,800$ & 97,340 & \\
\hline \multicolumn{7}{c}{ Variação na quantidade importada no país $(\Delta \%)$} & $-2,540$ \\
\hline$-11,270$ & $-0,820$ & $-5,710$ & 2,150 & $-50,950$ & -20 \\
\hline \multicolumn{7}{c}{ Variação na quantidade exportada no país $(\Delta \%)$} \\
\hline
\end{tabular}

Fonte: Elaboração própria a partir dos resultados do GTAP. 
Com o incentivo à produção dado pelo governo, os demais países produtores são afetados, de forma a apresentar diminuições relativas no volume de soja produzido e exportado. O impacto dessa diminuição é mais acentuado no Brasil, sendo seguido pela Argentina e pelos Estados Unidos, com quedas de $11,8 \%, 10,8 \%$ e $14,22 \%$, respectivamente. A China, em contrapartida, aumenta a quantidade produzida internamente em praticamente o dobro, apresentando um aumento de 97\%. Em decorrência do maior volume produzido pela China e com a diminuição dessa quantidade nos outros países, tem-se uma mudança no mercado internacional. A China tem suas quantidades exportadas mais do que triplicadas, com variação de $320,51 \%$; já o Brasil, a Argentina e os Estados Unidos comportam-se de forma a diminuir sua pauta exportadora do complexo, com quedas de $30 \%$, 27\% e $38 \%$ do volume exportado.

A Argentina mostra-se como o país que sofreu variações mais acentuadas devido a essa maior participação chinesa no mercado. O volume importado pela Argentina foi o que mais diminuiu, acompanhado do volume exportado, tornando-a a nação com a balança comercial mais afetada.

Tendo em vista a maior participação chinesa nas trocas comerciais da soja internacionalmente, deve-se atrelar esse fato a variações nos preços de comercialização. Todos os países exportadores apresentaram reduções nos preços, e a China, devido ao aumento significativo da produção, apresentou a queda mais drástica, com redução de $40 \%$, sendo seguida pela soja argentina, norte-americana e a brasileira.

A União Europeia, em meio a esse novo cenário produtivo e comercial, teve a quantidade importada de soja elevada e a exportada reduzida. Nota-se, pela Tabela 3, que essas variações não ocorreram nos mesmos patamares, pois as importações variaram positivamente em $1,40 \%$ enquanto as exportações reduziram em $11,27 \%$, retratando uma perda em termos de balança comercial significativo.

\subsection{Cenário 4: China decide subsidiar $100 \%$ da produção e $50 \%$ das suas exportações de soja}

Nesse quarto cenário, o governo chinês decide adotar uma política drástica que tende a afetar todo o comércio internacional do complexo de soja. Com a intenção de tornar a soja chinesa presente nos mercados internacionais, $o$ governo incentiva a produção e também as exportações, onerando o produtor e comerciante de forma a reduzir o preço da soja chinesa em relação às produzidas pelos demais países, além de fomentar a produção doméstica. A Tabela 4 retrata as mudanças vistas no cenário internacional em decorrência da adoção dessa política de incentivo pelo governo da China. 
SANGUINET, E. R.; CORONEL, D. A.; Políticas de Comércio Internacional: uma análise para o comércio da soja

TABELA 4 - VARIAÇÕES DECORRENTES DA DECISÃO CHINESA EM INCENTIVAR A PRODUÇÃO E O COMÉRCIO DA SOJA NACIONAL

\begin{tabular}{cccccc}
\hline \multicolumn{7}{c}{ Variação nos preços relativos de importação $(\Delta \%)$} \\
\hline $\begin{array}{c}\text { União } \\
\text { Europeia }\end{array}$ & $\begin{array}{c}\text { Resto do } \\
\text { Mundo }\end{array}$ & Argentina & $\begin{array}{c}\text { Estados } \\
\text { Unidos }\end{array}$ & China & Brasil \\
\hline$-0,850$ & $-2,170$ & $-3,140$ & $-2,410$ & $-35,320$ & $-2,020$ \\
\hline \multicolumn{7}{c}{ Variação na quantidade produzida internamente $(\Delta \%)$} \\
\hline$-9,780$ & $-8,910$ & $-12,140$ & $-14,700$ & 150,190 & $-16,670$ \\
\hline 3,360 & $-1,610$ & $-4,720$ & 10,520 & $-44,110$ & $-1,240$ \\
\hline \multicolumn{7}{c}{ Variação na quantidade importada no país $(\Delta \%)$} \\
\hline Variação na quantidade exportada no país $(\Delta \%)$ \\
\hline
\end{tabular}

Fonte: Elaboração própria a partir dos resultados do GTAP.

A União Europeia mostra-se como o grupo de países que teve o preço de venda da sua soja menos afetado, apresentando uma diminuição de apenas $0,85 \%$, fato que pode ter relação com a falta de competitividade da soja produzida em decorrência de baixas taxas de produção na União Europeia. A balança comercial da União Europeia mostrou mudanças abruptas, onde as exportações caíram cerca de $25 \%$ e as importações aumentaram 3,36\%.

O Brasil, a Argentina, os Estados Unidos e os demais países apresentaram queda nos preços de venda da soja, mas com variações não acima de $3 \%$. A China, por sua vez, teve uma diminuição considerável (e esperada) nos preços de venda de sua soja, com queda de $35 \%$.

A diminuição nos preços da soja chinesa é decorrência da política de incentivos do governo e do aumento da oferta, que também foi fruto desses incentivos. A quantidade produzida na China elevou-se em 150,19\%, enquanto os outros países analisados apresentaram queda, como no Brasil (-16\%), Argentina (-12\%), Estados Unidos (-14\%) e demais países $(-8,91 \%)$.

As quantidades exportadas responderam às intenções do governo chinês, nesse cenário, com aumento de $746,77 \%$ das exportações chinesas. Os países concorrentes tiveram suas quantidades reduzidas, sendo a Argentina o país mais afetado, apresentando redução de 39,10\% no nível de exportações. Essa reestruturação no mercado internacional de soja faz com que os Estados Unidos passe a comprar soja produzida por outros países, tendo suas importações elevadas em cerca de 10\%, enquanto Brasil e Argentina têm as importações reduzidas. 


\section{Conclusões}

O comércio internacional do complexo de soja tem caráter concentrador, sendo caracterizado pelo domínio produtivo de um número reduzido de países, onde estão a Argentina, os Estados Unidos e o Brasil. Devido à disponibilidade de recursos naturais propícios para a produção de soja e também de programas de incentivos governamentais específicos para fomentar a produção e comercialização dos produtos da soja, esses países ganham destaque nesse setor. Em contrapartida, tem-se que a China e a União Europeia destacam-se como sendo os principais compradores da soja produzida pelos três países, também devido à disponibilidade de recursos naturais internos e incentivos governamentais para a compra.

Tendo como prerrogativa básica que a adoção de determinadas políticas comerciais pelos países influencia todo o comércio entre nações, inferiu-se que informações sobre os possíveis efeitos dessas adoções tornam-se essenciais para auxiliar os países no processo de negociação internacional.

Os cenários foram criados com base em algumas políticas comerciais que tanto os países exportadores quanto os importadores poderiam adotar. Quatro cenários foram simulados na primeira etapa da pesquisa: a) a China decide eliminar tarifas de importação dos produtos de soja provindos do Brasil, da Argentina e dos Estados Unidos; b) os principais exportadores decidem, simultaneamente, subsidiar metade de suas produções domésticas; c) a China decide subsidiar metade da produção interna; d) e, o governo chinês decide subsidiar metade da produção e metade das exportações.

Os resultados dessa etapa apontaram que a adoção de políticas protecionistas de imposição de barreiras e/ou incentivos para o comércio por um país impacta de forma significativa as relações comerciais entre os países. A exemplo disso, no cenário onde se simulou que a China elimina tarifas de importação para os principais exportadores, os efeitos para o mercado foram de elevação dos preços e das quantidades exportadas para esses três países e redução do preço da soja chinesa. Essa medida de eliminação de barreiras promovida pela China gerou distorções no mercado, ao passo que beneficiou os exportadores e prejudicou a produção e a balança comercial chinesa. $\mathrm{O}$ segundo cenário foi de incentivo à produção pelos exportadores, onde se viu que promovem a redução drástica dos preços de venda desses países, devido ao aumento considerável na quantidade produzida. Os países importadores são os mais beneficiados.

Em dois dos cenários simulados, a China adotou medidas de incentivo à produção e/ou exportação dos produtos do complexo de soja, e essas medidas promoveram mudanças na conjuntura comercial até então firmada entre os 
países. Essas medidas de incentivo chinês promoveram a reafirmação da soja chinesa no mercado internacional, prejudicando a balança comercial dos, até então, principais exportadores. Deve-se isso à queda nos preços da soja chinesa em âmbito internacional, em decorrência de uma maior oferta no mercado, tornando a competição via preços algo desigual.

Tendo em vista as distorções que determinadas atitudes protecionistas podem gerar nos mercados, torna-se de suma importância o papel desempenhado por instituições como a OMC, na medida em que podem inibir os países de tomar decisões que incorram em prejuízos comerciais descomunais para países que não têm condições naturais e estruturais de competição internacional.

Como limitação deste estudo e de alguns outros trabalhos que utilizam as tarifas do GTAP, está o fato de aplicar choques de políticas que possam superestimar efeitos sobre o comércio, sem levar em consideração as diferenças entre tarifas aplicadas e consolidadas. Nesse sentido, justificou-se a simulação de cenários que possam não condizer tanto com a realidade, devido à possibilidade de avaliar grandes choques de cunho macroeconômico nas relações de compra entre nações.

Por fim, sugerem-se novos trabalhos que busquem meios de avaliar os efeitos de outras variáveis, tais como custos de transporte e de mudanças de ordem política, além dos efeitos sobre produção, consumo e fluxos comerciais entre países, para que se avaliem de forma mais detalhada as vantagens competitivas existentes entre os países. Recomenda-se também outros estudos que analisem a inserção do Brasil no comércio internacional do complexo de soja e de outros produtos relevantes para balança a comercial brasileira, considerando, além do uso de tarifas, outros mecanismos de proteção comercial como quotas tarifárias, subsídios e barreiras não tarifárias.

\section{Referências Bibliográficas}

Brandão, Antônio S.; Lima, Elcyon. C. R. (2002) Impacts of the US Subsidy to soybeans on Brazilian Production and Exports. Revista de Economia e Sociologia Rural 44 (4): 631-676.

Conforti, Pierro; Salvatici, Luca. (2004). Agricultural Trade Liberalization in the Doha Round. Alternative Scena- rios and Strategic Interactions Between Developed and Developing Countries. $7^{\text {th }}$ Annual Conference on Global Economic Analysis: 17-19. Disponível em: < (http://www.gtap.agecon.purdue.edu>). Acesso em: 12 de setembro de 2013.

Coronel, Daniel A. (2008) Fontes de crescimento e orientação regional das exportações brasileiras do complexo soja. (Dissertação de Mestrado em Agronegócios) Programa de Pós-Graduação em Agronegócios, Centro de Estudos e Pesquisas em Agronegócios, Universidade Federal do Rio Grande do Sul, Porto Alegre. 2008. 
Coronel, Daniel A.; Machado, João A. D.; Carvalho, Fátima M. A. (2009). Análise da competitividade das exportações do complexo de soja brasileiro de 1995 a 2006: Uma abordagem de market-share. Revista Economia contemporânea 13(2): 281-30. 2009.

Costa, Cássia K. F. (2012). Impacto dos subsídios sobre as exportações dps complexos soja e suco de laranja do Brasil: abordagem pela teoria dos jogos. (Dissertação de Mestrado em Economia) - Programa de Pós-Graduação em Economia, Universidade Federal da Paraíba (UFPB), João Pessoa, 2012.

Figueiredo, Adriano M. R.; Ferreira; Adriana A.; Teixeira, Erly C. (2001). Impactos da integração econômica nas Commodities da Economia Brasileira e da União Europeia. Revista Brasileira de Economia 55(1): 77-106. 2001.

Flôres, Renato G. The gains from Mercosul: A general equilibrium, imperfect competition evaluation. (1997). Journal of Policy Modeling, 19(1):1-18. 1997.

Food and Agriculture Organization of the United Nations (FAO). (2014). Statistics Data of Trade. Disponível em <http://faostat.fao.org/>. Acesso em: 17 de julho de 2014 .

Gurgel, Ângelo C.; Pereira, Matheus W. G.; Teixeira, Erly C. (2010) A estrutura do PAEG. PAEG Technical Paper No.1. Viçosa: DER/UFV. 2010.

Lower, Michael E. (2002). Brazil Oilseeds and Products Annual 2002. USDA Foreign Agricultural Service, FAS, GAIN Report. 2002.

Nassar, André M. (2004) Produtos da agroindústria de exportação brasileira: uma análise das barreiras tarifárias impostas por Estados Unidos e União Europeia. Tese (Doutorado em Administração) - Faculdade de Economia, Administração e Contabilidade, Universidade Estadual de São Paulo, São Paulo, 2004.

Reetz, Erna. (2006) Anuário brasileiro da soja 2006. Santa Cruz do Sul: Gazeta, 136 p. 2006.

Sampaio, Luciano M. B.; Sampaio, Yony. (2007). Prioridade brasileira entre acordos de livre comércio: uma aplicação de equilíbrio geral aliado à teoria dos jogos. In: Anais do Encontro Nacional de Economia (ANPEC), Recife. 2007. Disponível em: <http://www.anpec.org.br/encontro2007/artigos/A07A077.pdf>. Acesso em: 16 de julho de 2013 .

Sampaio, Luciano M. B.; Sampaio, Yony; COSTA, Écio de F. (2006). Mudanças políticas recentes e competitividade no mercado internacional de soja. Revista de Economia e Sociologia Rural 44(3):383-411. 2006.

Schmidtke, Claucir R.; Shikida, Pery F. A. (2008). Políticas Comerciais: Uma Revisita à Guisa da Literatura. Revista Economia \& Tecnologia 04(14): Julho/ Setembro de 2008.

Secretaria de Comércio Exterior (SECEX). (2008). Disponível em: <http://www. mdic.gov.br/sitio/secex/secex/informativo.php $>$. Acesso em: 20 de abril de 2013.

Susanto, Dwi. (2006). Measuring the Degree of Market Power in the Export Demand for Soybean Complex. Tese (Doutorado em Filosofia). Department of Agricultural Economics and Agribuness. Estados Unidos, 2006. 189 f. Disponível em: <http://etd.lsu.edu/docs/available/etd-12082005-112815/unrestricted/ Susanto_dis.pdf>. Acesso em: 15 de outubro de 2013. 
SANGUINET, E. R.; CORONEL, D. A.; Políticas de Comércio Internacional: uma análise para o comércio da soja

Valerini, Juliana. P. (2006). O mercado da soja: Evolução da commodity frente aos mercados internacional e doméstico. Revista Jovens Pesquisadores Mackenzie 4(1): Janeiro/Junho de 2006.

Verdonk, Richard. (2003). Brazil Oilseeds and Products Annual 2003. USDA Foreign Agricultural Service, FAS, GAIN Report. Disponível em <http://www.fas.usda. gov>. Acesso em: 22 novembro de 2013.

Vianna, Catarina C.; LIMA, João P. (2010). Política comercial brasileira: possíveis impactos de uma redução nas tarifas de importação dos setores automotivo e têxtil. Revista Econômica 12(2): 157-186. 2010.

Yu, Wusheng.; FRANDSEN, Soren E. (2005). China's WTO Commitments in Agriculture: Does the Impact Depend on OECD Agricultural Policies? 5th Annual Conference on Global Economics Analysis, Taipei and International Conference on China and the World Economy, Hong Kong. 2005. 